\title{
La momia de Nesiamón del Metropolitan Museum of Art de Nueva York: ¿accidente o trasplante para la eternidad?
}

Miguel A. SÁNCHEZ

El Metropolitan Museum of Art de Nueva York ha presentado en otoño de 2005 una exposición sobre la Medicina en el Egipto antiguo. Una de las piezas más sorprendentes es la momia sin desvendar de Nesiamón, un individuo del que desconocemos los cargos que ocupó y que debió de vivir durante la dinastía XXV, acompañada de su examen radiológico por medio de un TAC. La interpretación de los hallazgos radiológicos, por los miembros del Grupo de Estudios de Momias del Museo, ya publicado anteriormente, consiste en que el cuerpo de Nesiamón muestra una patología resultado de un accidente. Describen fracturas de cráneo, del húmero derecho y de la pelvis izquierda. También huesos extrínsecos y bastones de papiro. La explicación de estos últimos elementos es que fueron "usados por los embalsamadores para estabilizar el cuerpo". La interpretación alternativa que proponemos es que Nesiamón sufría una serie de alteraciones óseas muy antiguas (puede que congénitas) y que los elementos introducidos son un intento de "completar" el cuerpo para la otra vida, un trasplante para la eternidad.

The mummy of Nesiamun at the New York Metropolitan Museum of Art: Accident or transplant for eternity?

During the Fall season 2005, the Metropolitan Museum of Art held an exhibition about Ancient Egyptian Medicine. One of the most striking pieces was the mummy of Nesiamun, a XXV Dynasty unwrapped mummy, accompanied by an image of its CAT scan. The Museum's interpretation of the radiological findings, previously published, stated that Nesiamun shows pathology consistent with an accident. They describe skull, right humerus and left pelvis fractures. There are also exogenous bones and papyrus rods. The Museum explanation of these last findings is that the embalmers used them to stabilize the body. An alternative interpretation that we offer is that Nesiamun had suffered a series of long-standing skeletal alterations, probably congenital, and the added bones and rods are an attempt to "complete" the body for the after life, a transplant for eternity.

KEY wORDs: Thebes, 25th Dynasty, Nesiamun, mummy, pathology, scoliosis

$\mathrm{E}_{\mathrm{d}}^{\mathrm{n}}$ ntre los meses de septiembre de 2005 y enero de 2006, el Metropolitan Museum of Art organizó una exposición llamada "El Arte de la Medicina en el Antiguo Egipto". Se componía casi exclusivamente de objetos de la colección del propio museo, con la excepción del papiro Edwin Smith.

La exposición no era muy grande e incluía piezas de diferentes periodos de la historia del

Fecha de recepción: 30 de mayo de 2007
Egipto antiguo, todos relacionados con aspectos médicos. Objetos prehistóricos compartían el espacio con material de la época grecorromana.

Tres objetos se convirtieron en el centro de atracción: la estela de Metternich, del reinado de Nectanebo II, con sus oraciones para la prevención y el tratamiento de picaduras de escorpión y los mordiscos de serpiente; el papiro Edwin

Fecha de aceptación: 25 de junio de 2007 


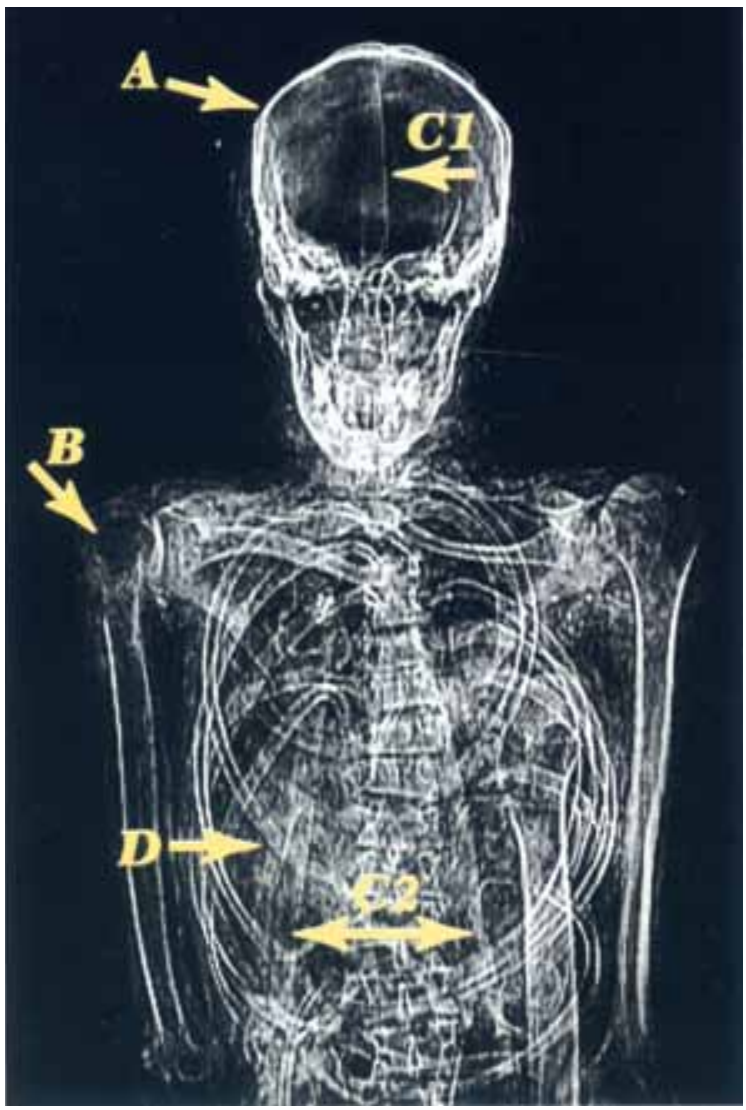

Figura 1

TAC del tórax de la momia de Nesiamón que muestra fracturas de cráneo (A) y húmero derecho $(B)$, además de varas, posiblemente de papiro $(C)$ en la cabeza y región paraespinal. El periosteo del brazo derecho es mucho mas fino que el del otro lado. El húmero derecho es claramente más corto que el izquierdo y la cabeza del húmero derecho más pequeña que la del otro lado. En el lado izquierdo del tórax se observa parte de hueso largo, probablemente el fémur. La columna vertebral es claramente

Smith, probablemente el objeto más valioso, exhibido como préstamo de la New York Academy of Medicine; y la momia vendada de Nesiamón, que es el objetivo de esta comunicación. El cuerpo momificado de Nesiamón fue encontrado por la expedición del Metropolitan Museum durante la excavación de 1922-1923 en Tebas. Estaba enterrado en una tumba del Reino Me-

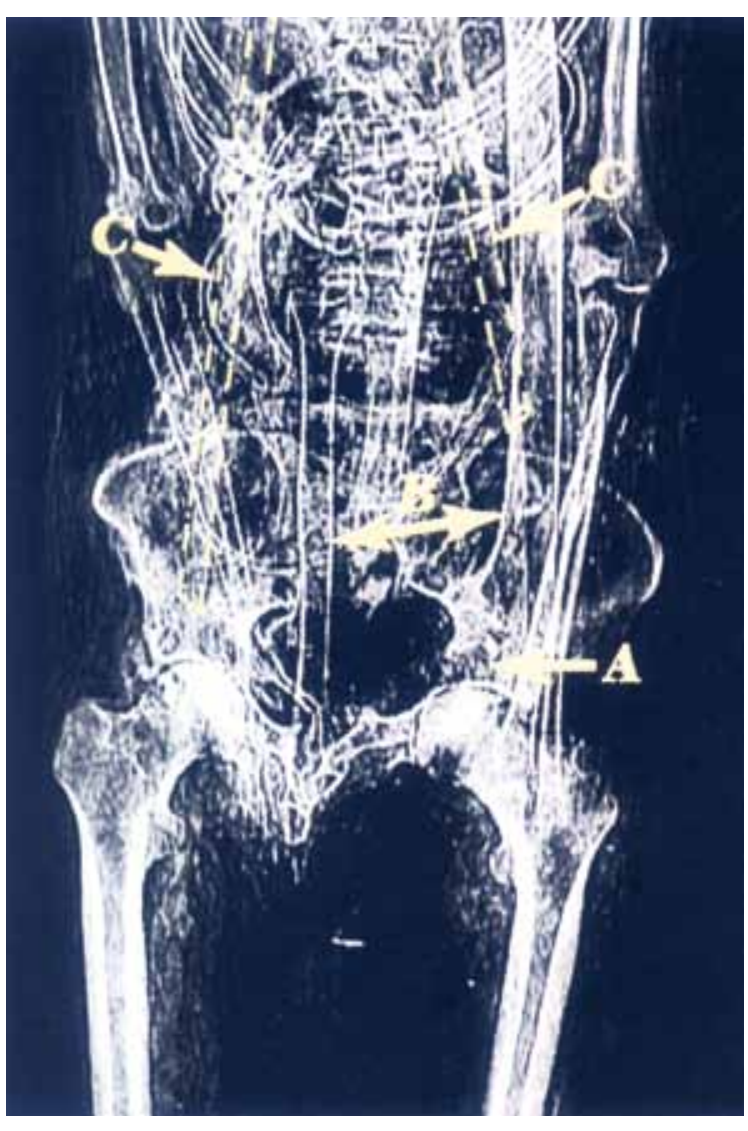

Figura 2

A: fractura de pelvis

B: continuación de los huesos exógenos C: palos paraespinales

dio, cerca del templo funerario de Montuhotep II. El Museo considera, por razones de estilo y el lugar de procedencia, que pertenece a la Dinastía XXV. Una inscripción muestra la fórmula común de ofrenda, e identifica al difunto. La momia se encontró intacta y como parte de un proyecto del Museo, fue estudiada por medio de una Tomografía Axial Computarizada (TAC). Por esta razón, una composición radiológica del esqueleto formaba parte del la exposición.

\section{El texto del catálogo menciona:}

Although his mummy has never been unwrapped, a recent CAT (computer-assisted tomography) scan revealed that Nesiamun was $166 \mathrm{~cm}(\ldots)$ tall and 
sustained several serious injuries before death. (...) gross disruption of his ribs, a fracture of the right humerus, and a linear skull fracture. The fracture site in the humerus is surrounded by healing bone (callus), indicating that Nesiamun lived for several weeks after his injuries. (...) fracture of the pelvis and the odd placement by the embalmers of extraneous bones within his abdominal cavity, along with two rod-like structures on either side of his spine; a third rod occupies the center of his spinal column, apparently displacing the nerves and spinal cord. (...) Nesiamun's trauma was probably the result of a vehicular accident. The impact of a chariot or horse could have caused the broken pelvis, with the other fractures secondary to the fall. (...) he was a military casualty or that he was injured while working on a building project. The extraneous bones and rods were placed by the embalmers probably in order to stabilize Nesiamun's badly damaged body. The New York Botanical Garden has identified the rods as either cyperus papyrus or the center rib of a date palm frond ${ }^{1}$.

Si miramos las radiografías, podemos confirmar algunas de las observaciones. Hay una fractura con callo reactivo en el húmero derecho, lo que quiere decir que los tejidos blandos han reaccionado, por lo que la rotura de los huesos ocurrió antes de la muerte de Nesiamón. También hay fracturas de cráneo y pelvis y unos huesos extraños y unos palos situados de forma lateral a la columna vertebral. Estos hallazgos ya habían sido publicados previamente. D. T. Mininberg había presentado un informe completo en la revista de divulgación egiptológica $K M T$ y una revisión técnica en la revista Neurosurgery ${ }^{2}$.

El primer problema, no muy serio, es que en estos dos informes las fracturas de húmero y cráneo se describen en el lado izquierdo. Está claro, por tanto, que o el catálogo o los informes han invertido las fotografías de las radiografías del tórax. El problema es que los textos explicativos coinciden con las placas radiográficas res- pectivas en los diferentes informes. Los editores invierten radiografías constantemente, pero aquí el texto se ha modificado para que coincida con las imágenes.

A continuación, si analizamos el TAC como si hiciéramos el estudio de un enfermo y no para comprobar lo que se nos dice en el texto, el análisis es muy diferente.

En primer lugar, se ve una fractura de húmero (a la derecha en el catálogo) pero el periostio, la parte externa del hueso, es mucho más fino que el del otro lado. La disminución del grosor de un hueso solo ocurre con inactividad muy prolongada. El que encontramos en este caso, es mucho más que lo que se espera tras unas semanas de inmovilidad. Pero esto no es todo con respecto al brazo derecho. La longitud del húmero es claramente más corta que la del otro lado y la cabeza del húmero más pequeña. Una fractura únicamente se asocia con cambio de longitud si ocurre durante el periodo de crecimiento y tras una inmovilización muy prolongada. La columna vertebral también es muy anormal. Los cuerpos vertebrales sufren los cambios típicos de una escoliosis severa. No solamente la columna está curvada sino que se ve claramente que los cuerpos vertebrales son más estrechos en un lado que en el otro, muy típico de escoliosis de larga duración. La fractura pélvica no se observa con la misma claridad que la humeral, pero parece cierta. También da la impresión de una asimetría en la pelvis. También esta presente una fractura de cráneo, pero no hay reacción de tejidos blandos. Esto no es muy raro en este tipo de fracturas, pero tampoco sería imposible que las fracturas humeral y craneana, sean de diferentes periodos.

Los huesos exógenos se encuentran dentro de la cavidad torácico-abdominal. A la izquier-

1. David T. Mininberg en Allen, 2005: 36-37.

2. Mininberg, 2000 y 2001, respectivamente. 
da hay un hueso muy largo que, si es humano, representa el fémur y, si no lo es, al menos podemos afirmar que formaba parte de una extremidad. En el lado derecho los huesos no se ven tan bien pero parecen un húmero $\mathrm{y}$ dos huesos largos contiguos, posiblemente cubito y radio. Los palos se han emplazado lateral y simétricamente a los lados de la columna vertebral.

Lo que tenemos, desde el punto de vista clínico, es un verdadero discapacitado con escoliosis severa, un brazo atrófico, casi seguramente congénito, y una pierna que tampoco pudo funcionar bien.

La reinterpretación del TAC abre paso a una reconstrucción diferente de la vida de Nesiamón y representa una posible conexión entre los ritos de momificación y el deseo de completar el cuerpo del difunto, dándole las partes que eran deficientes durante su vida. También nos da la posibilidad de analizar la actitud de los antiguos egipcios con algunos minusválidos.

Nesiamón vivió posiblemente hasta cerca de los 50 años. Sufría grandes deficiencias esqueléticas que le impedirían realizar trabajo físico y que harían imprescindible que necesitara ayuda diaria para sobrevivir. No sólo el tipo de momificación está claramente relacionado con una situación económica pudiente, sino que Nesiamón recibió atención continua durante muchos años.

De gran interés es el hecho de que los palos colocados a los lados de la columna parecen tener la intención de estirar el cuerpo de un hombre con gran escoliosis. A su vez, el fémur y los probables húmero, cúbito y radio, puede que representen el deseo de "trasplantar" a Nesiamón las extremidades que eran deficientes durante su vida. Proponemos, por tanto, calificarlos con el término de "trasplante o prótesis para la eternidad". 


\section{Bibliografía}

Allen, J. P.

MininBerG, D. T.

2005 The Art of Medicine in Ancient Egypt. New 2000 A 25th Dynasty Vehicular Accident, KMT York / New Haven / London.

11 (3, Fall): 60-66.

2001 The Museum Mummies, Neurosurgery 49 (1, July): 192-199. 


\section{Trabajos de Egiptología Papers on Ancient Egypt}

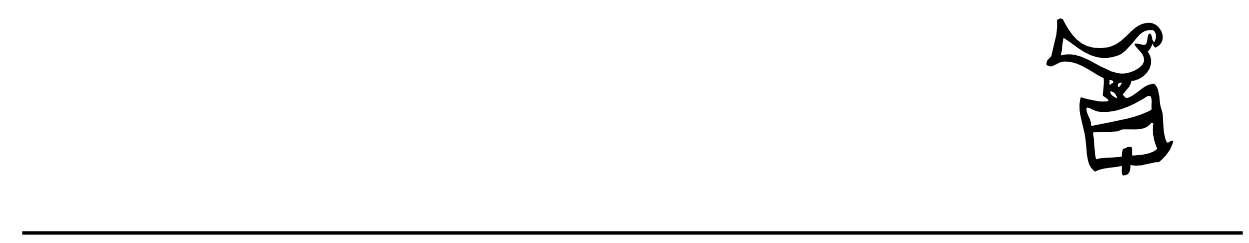

Número 5/2 2009 


\section{Actas \\ III Congreso Ibérico de Egiptología III Congresso Ibérico de Egiptologia}

Editores

Miguel Ángel Molinero Polo Covadonga Sevilla Cueva 


\title{
Editor
}

Miguel Ángel Molinero Polo

Universidad de La Laguna

\section{Consejo Editorial}

\author{
Antonio Pérez Largacha \\ Universidad de Castilla-La Mancha \\ José-R. Pérez-Accino \\ Birkbeck, Universidad de Londres \\ Covadonga Sevilla Cueva \\ Universidad Autónoma de Madrid
}

\section{Comité Científico}

Josep Cervelló i Autuori

Universitat Autònoma de Barcelona

$\mathrm{M}^{\mathrm{a}}$ José lópez Grande

Universidad Autónoma de Madrid

Josep Padró i Parcerisa

Universitat de Barcelona

$\mathrm{M}^{\mathrm{a}}$ Carmen Pérez Die

Museo Arqueológico Nacional, Madrid

Ester Pons Mellado

Museo Arqueológico Nacional, Madrid

José M. Serrano Delgado

Universidad de Sevilla

\section{Colaboradores Editoriales}

Linda Steynor

English editorial assistant

Hervé Mouriacoux

Assistant éditorial pour la langue française 
Trabajos de Egiptología está producida por Isfet. Egiptología e Historia c/ Blanco $1,2^{\circ}$

38400 Puerto de la Cruz

Tenerife-Islas Canarias

España

Maquetación: Proyecto Limón

(C) Autores de los artículos aparecidos

y Consejo Editorial de Trabajos de Egiptología - Papers on ancient Egypt

Depósito Legal: TF-2303-2009

ISSN: $1695-4750$

Imprime: Gráfica Los Majuelos, S.L.L.

imprenta@graficaslosmajuelos.com

Tfno.: 922311455 


\section{Comité Científico \\ III Congreso Ibérico de Egiptología III Congresso Ibérico de Egiptologia}

Miguel Á. Molinero Polo

Universidad de La Laguna

Presidente del Comité Organizador del III Congreso Ibérico de Egiptología

Miembro del Comité Organizador del I Encuentro de Egiptología

Josep Cervelló Autuori

Universitat Autònoma de Barcelona

Presidente del Comité Organizador del II Congreso Ibérico de Egiptologia

José Manuel Galán Allué

Consejo Superior de Investigaciones Cientificas

Director del Proyecto Djehuty, Luxor, Egipto

$\mathrm{M}^{\mathrm{a}}$ Helena Trindade Lopes

Universidad de Lisboa

Directora de la Misión Arqueológica Portuguesa en Menfis

Josep Padró i Parcerisa

Universitat de Barcelona

Director de la Misión Arqueológica de Oxirrinco

Antonio Pérez Largacha

Universidad de Castilla - La Mancha

Miembro del Comité Organizador del I Encuentro de Egiptología

José Ramón Pérez-Accino

Birkbeck College, University of London

Miembro del Comité Organizador del I Encuentro de Egiptología

$\mathrm{M}^{\mathrm{a}}$. Carmen Pérez Díe

Museo Arqueológico Nacional

Directora de la Misión Arqueológica Española en Heracleópolis Magna, Egipto

Covadonga Sevilla Cueva

Universidad Autónoma de Madrid

Miembro del Comité Organizador del I Encuentro de Egiptología 